This PDF is a selection from a published volume from the National Bureau of Economic Research

Volume Title: Discoveries in the Economics of Aging

Volume Author/Editor: David A. Wise, editor

Volume Publisher: University of Chicago Press

Volume ISBN: 0-226-14609-X (cloth); 978-0-226-14609-6 (cloth); 978-0-226-14612-6 (EISBN)

Volume URL: http://www.nber.org/books/wise13-1

Conference Date: May 9-11, 2013

Publication Date: June 2014

Chapter Title: The Lifetime Risk of Nursing Home Use

Chapter Author(s): Michael D. Hurd, Pierre-Carl Michaud, Susann Rohwedder

Chapter URL: http://www.nber.org/chapters/c12970

Chapter pages in book: (p. 81 - 109) 


\title{
The Lifetime Risk of Nursing Home Use
}

\author{
Michael D. Hurd, Pierre-Carl Michaud, and \\ Susann Rohwedder
}

\subsection{Introduction}

The risk of spending for long-term care is one of the most important risks faced by older households because of the long right tail of days spent in nursing homes. However, finding data to estimate the risk has been difficult because of the necessity of following individuals over long periods of time. In this study, we use data from the Health and Retirement Study (HRS) to assess the lifetime distribution of stays in nursing homes and what these indicate for long-term care risks faced by households. While the HRS only samples from the noninstitutionalized population at baseline, the follow-up of this longitudinal survey includes all baseline respondents, in particular those who move to a nursing home. As a result, after several waves the HRS will also represent the nursing home population because of turnover in nursing homes: almost all those in nursing homes at baseline will have died and been replaced by persons initially residing in the community and represented by HRS respondents. We use 10 waves of the HRS including cohorts added after the original HRS cohort, those born in the years 1931-1941. Those

Michael D. Hurd is director of the Center for the Study of Aging, a senior principal researcher at RAND, a fellow of NETSPAR, and a research associate of the National Bureau of Economic Research. Pierre-Carl Michaud is professor of economics at the University of Québec at Montréal and an affiliated adjunct economist with RAND. Susann Rohwedder is associate director of the Center for the Study of Aging, a senior economist at RAND, and a research fellow of NETSPAR.

This research was supported by the National Institute on Aging, under grant 1R01AG041116. We thank Joanna Carroll for excellent programming assistance and David Boisclair for editorial assistance. Any remaining errors are our own. For acknowledgments, sources of research support, and disclosure of the authors' material financial relationships, if any, please see http:// www.nber.org/chapters/c12970.ack. 
additional cohorts were added in years following the initial interview of the HRS cohort in 1992. In addition to the core interviews we use data from the proxy interviews, usually with a spouse or other close relative, for those unable to participate in a given interview wave. Most importantly we use data from exit interviews that are conducted with a proxy after the death of a respondent. Our use of all waves of all relevant HRS cohorts as well as exit interviews allows us to estimate lifetime risk of a nursing home stay both nonparametrically and with a flexible transition model, which we use to simulate nursing home histories.

\subsubsection{Prior Results}

The types of studies that are most relevant to ours are those that estimate the lifetime chances of ever being in a nursing home (lifetime risk), those that estimate durations of stays in nursing homes, either conditional on a stay or unconditional, and those that estimate the lifetime duration in nursing homes. With respect to the first category, lifetime risk, the estimates range up to 55 percent (Arling, Hagan, and Buhaug 1992). A widely cited rate is 37 percent for those over the age of sixty-five (Kemper and Murtaugh 1991), and there are a number of other similar estimates. ${ }^{1} \mathrm{~A}$ common finding is that lifetime risk is higher for women than for men, as for example, in Brown and Finkelstein (2008): 44 percent for women and 27 percent for men. As for durations of stay, there are often conditioning events that make comparisons across studies difficult. For example, Dick, Garber, and MaCurdy (1994) estimate the average length of stay to be twenty-one months conditional on entering. Arling, Hagan, and Buhaug (1992) estimate that on average individuals who have a nursing home stay will spend twenty-four months in a nursing home. Conditional on dying in a nursing home, the mean length of stay estimated over the seven waves of AHEAD data was fourteen months (Kelly et al. 2010). The average total time spent in nursing homes over a lifetime, counting multiple stays, was estimated to be 2.3 years in Liang et al. (1996). Regardless of the exact estimate, the duration of individual stays and of accumulated lifetime stays is substantial, putting individuals that must pay out of pocket at considerable financial risk.

\subsection{Data}

\subsubsection{The HRS}

Our analyses are based on data from the Health and Retirement Study (HRS). The HRS is a biennial longitudinal survey that covers a broad range of topics including income, work, assets, pension plans, health insurance,

1. See Cohen, Tell, and Wallack (1986), Dick, Garber, and MaCurdy (1994), and Spillman and Lubitz (2002). 
disability, physical health and functioning, cognitive functioning, and health care expenditures. Its first wave was conducted in 1992. The target population was the cohorts born in 1931-1941, also called the original HRS cohort (Juster and Suzman 1995). Additional cohorts were added in 1993 of those born in 1923 or earlier (AHEAD cohort), in 1998 of those born between 1924 and 1930 (Children of the Depression Age [CODA] cohort), and of those born between 1942 and 1947 (War Babies), so that in 1998 the HRS represented the population of at least fifty-one years of age. New cohorts have subsequently been added every six years, including, in 2004, Early Baby Boomers born from 1948 to 1953, again making the HRS representative of the population age fifty-one or older.

Every cohort is sampled from the noninstitutionalized population at baseline so that the population residing in nursing homes is not represented. However, HRS makes extensive efforts to follow respondents after the baseline, including those who move into institutional settings such as nursing homes. Core interviews are conducted every two years. If a person is too frail or cognitively impaired to be interviewed, a proxy interview is conducted instead with a spouse or close relative. If a respondent dies between waves, HRS will attempt to conduct a so-called exit interview with a proxy informant, preferably someone who is knowledgeable about the family and financial situation and the circumstances preceding the person's death. Because nursing home stays are most prevalent among the frail, cognitively impaired, or those close to death, the information obtained in proxy and exit interviews is critical for assessing the prevalence and incidence of nursing home stays. If despite all efforts HRS cannot make contact with a respondent or any relative, the HRS conducts tracking efforts, with special emphasis on determining whether the respondent may have died. In these efforts HRS cross-checks data sources such as the Social Security Death Index and the National Death Index to ascertain whether the respondent has died.

Table 2.1 summarizes characteristics of the different cohorts included in the HRS. By the time wave 10 of the HRS was conducted in 2010, 14 percent of the oldest cohort was still alive, as was 79 percent of the youngest cohort. Vital status was unknown for few respondents in any wave. The HRS is quite successful in completing exit interviews with a proxy. For example, HRS gathered exit interviews for 96 percent of deceased respondents of the AHEAD cohort.

For all cohorts in the HRS, an analysis of nursing home stays will potentially suffer from either left censoring (do not observe nursing home spells prior to initial wave) or right censoring (do not follow until death so there could be spells beyond wave 10 in 2010). The importance of such censoring depends on the cohort and the initial age. For example, the subsample of AHEAD respondents who were age eighty-five at baseline in 1993 have all died by 2010. So there is no right censoring among this group of respondents, but there is considerable left censoring because no nursing home stays prior 


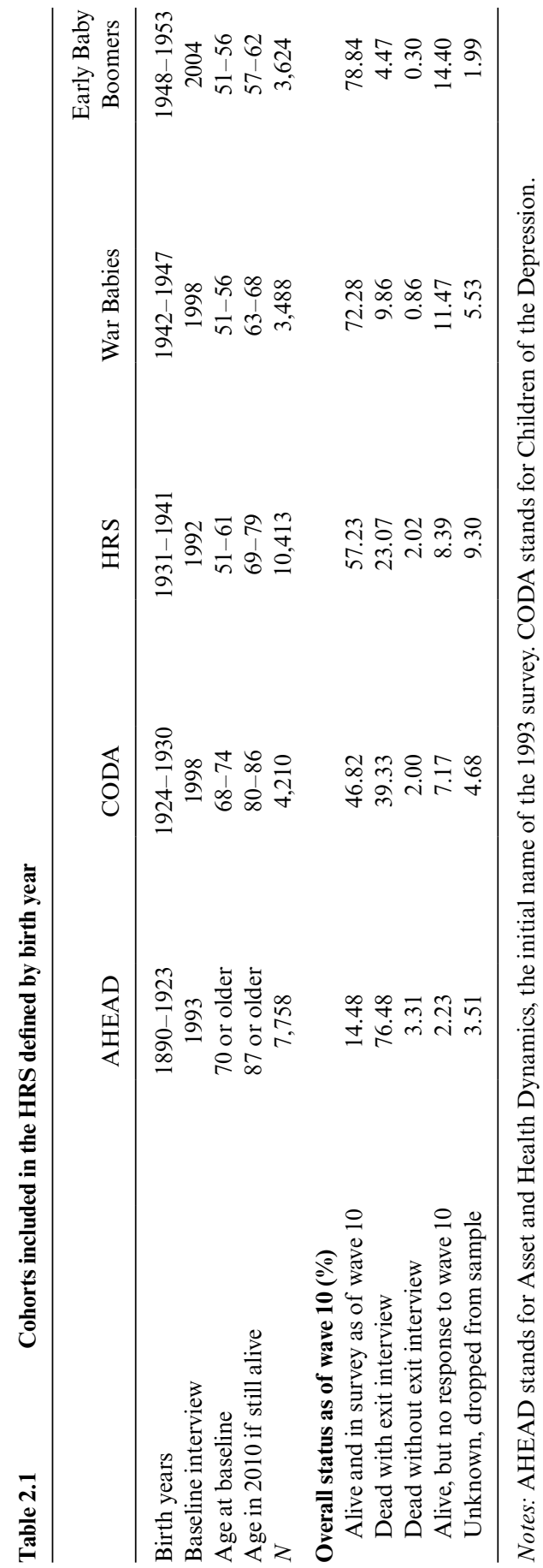


to age eighty-five have been observed for these respondents. Conversely, with younger HRS respondents, there is very little left censoring but considerable right censoring, because by 2010 they are still in their early seventies and the majority of their nursing home stays will still be in the future and is not observed in the data. Both parametric and nonparametric analyses will address these issues.

\subsubsection{Information on Nursing Home Stays in the HRS}

The HRS collects the following information on respondents' nursing home stays in the core HRS interview: ${ }^{2}$

- whether the respondent was residing in a nursing home at the time of interview

- if so, when the person moved to the nursing home (or if the person had stayed there continuously since the previous interview)

- whether the respondent had any (other) nursing home stay since the previous interview

- if so, how many nursing home stays in total

- if one stay, how many nights spent in nursing home

- if more than one stay, how many nights in total spent in nursing home

The HRS also asks about the month and year of the nursing home entry and exit for up to three spells, which can be used to cross-check or complement the information on the total number of nights spent in the nursing home.

The exit interviews ask for the same information with reference to the time between the last interview the respondent completed and the respondent's time of death. We integrate the information obtained in the exit interviews into our key outcome measures:

Any nursing home stay in the previous two years. For respondents who participated in a particular wave $t$ and in the immediately preceding wave $t-1$ this variable takes the value one if the person was in the nursing home either any time between waves or is currently in a nursing home at wave $t$. For those respondents who died between the two waves, we use the information obtained from the exit interviews. If those indicate that the respondent was in a nursing home any time between the preceding wave $t-1$ and the time of death, then this variable will take the value one in wave $t$. If someone missed one or more interviews this measure would cover a longer period. For most exit interviews the period covered averages about one year.

2. A respondent is asked about nursing home residence in the following way: "Are you living in a nursing home or other health care facility?" If a respondent asks for a definition, the following is read to him/her: "A nursing home or other health facility provides all of the following services for its residents: dispensing of medication, twenty-four-hour nursing assistance and supervision, personal assistance, and room and meals." 


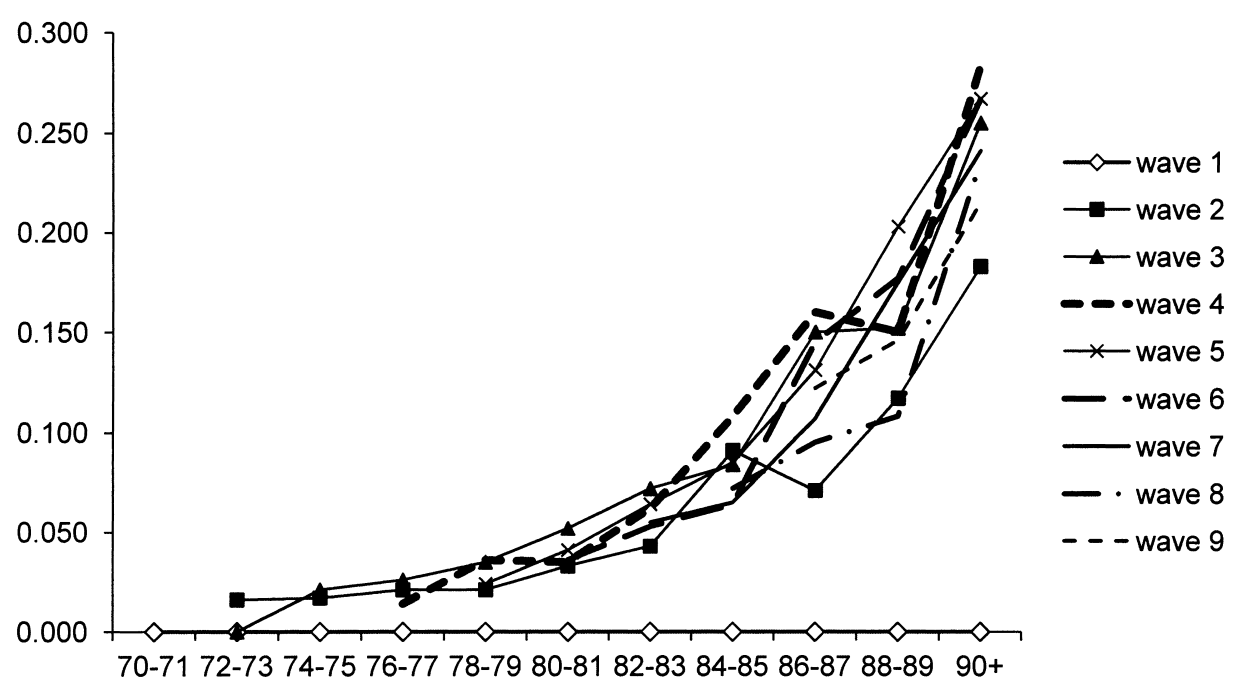

Fig. 2.1 Prevalence of respondents being in nursing home at the time of interview, by age and wave: AHEAD cohort

Number of nights spent in nursing home in the previous two years. The construction of this variable follows the same principle. It uses the information from the HRS core interview for all those respondents who survive, and the information from the exit interviews for those respondents who died between waves.

Lifetime measures of "any nursing home stay" and the "number of nights spent in a nursing home." These measures cumulate the survey information of any nursing home stay and the number of nights spent in a nursing home in the previous two years over all waves up to the last wave collected in the year 2010 .

\subsubsection{Population Representativeness with Respect to the Nursing Home Population}

The HRS draws its baseline sample from the noninstitutionalized population, but then follows up with all respondents, including when they move to nursing homes. We want to establish how many waves it takes until the HRS survey reaches population representation with respect to the nursing home population. Figure 2.1 shows the fraction in nursing home residence by age for each wave of the AHEAD cohort. Because the AHEAD wave 1 sample is drawn from the community, nursing home stay prevalence upon entering the study is zero at all ages. By wave 2, substantial numbers are living in a nursing home; for example, 7.1 percent of those $86-87$ years of age. Nonetheless, the curve for wave 2 mostly lies below the curves for later waves suggesting that after two years, nursing homes still had residents that 


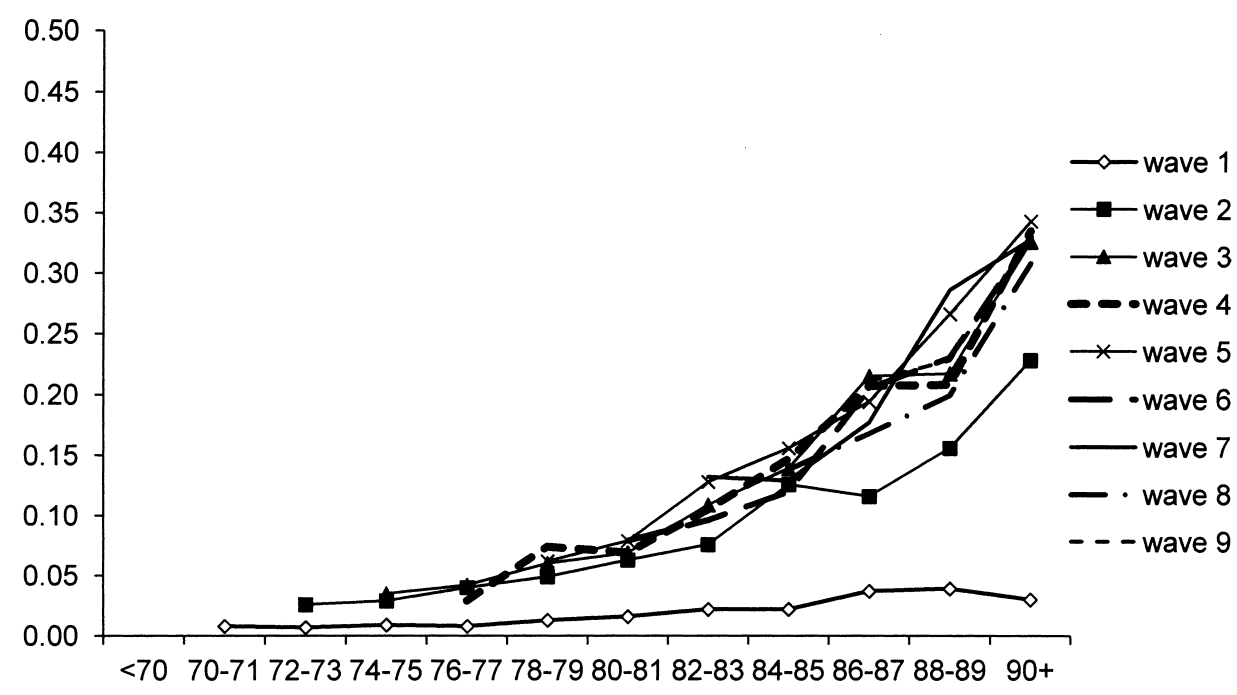

Fig. 2.2 Fraction with any nursing home stay in last two years, by age: AHEAD cohort (no exit interviews)

were not represented in the initial AHEAD wave. By wave 3 (1998) or five years after the baseline wave, the prevalence of residing in a nursing home was about the same as in later waves, leading us to surmise that by then, at least as far as prevalence is concerned, the AHEAD cohort was representative of the entire population, not just the community dwelling population. ${ }^{3}$ Thus in addition to left and right censoring, nonparametric estimation of the risk of any stay must account for start-up, the fact that the initial waves did not represent adequately the nursing home population.

2.2.4 The Importance of the Exit Interviews for Assessing Lifetime Nursing Home Exposure

Some nursing home stays are short term, beginning and ending between waves. As a result, the measure of nursing home residence at the time of interview is not suitable for measuring lifetime exposure. Figure 2.2 adds exposure between waves. It shows, for example, that among those 86-87 years old in wave $2,11.6$ percent had nursing home exposure between wave 1 and wave 2 (including residence at wave 2) but just 7.1 percent were in residence (figure 2.1). This indicates the importance of shorter-term stays. The figure shows that by wave 3 , nursing home exposure between waves was at about the same level as in later waves, again illustrating that the first two waves cannot be used to show nursing home exposure. 


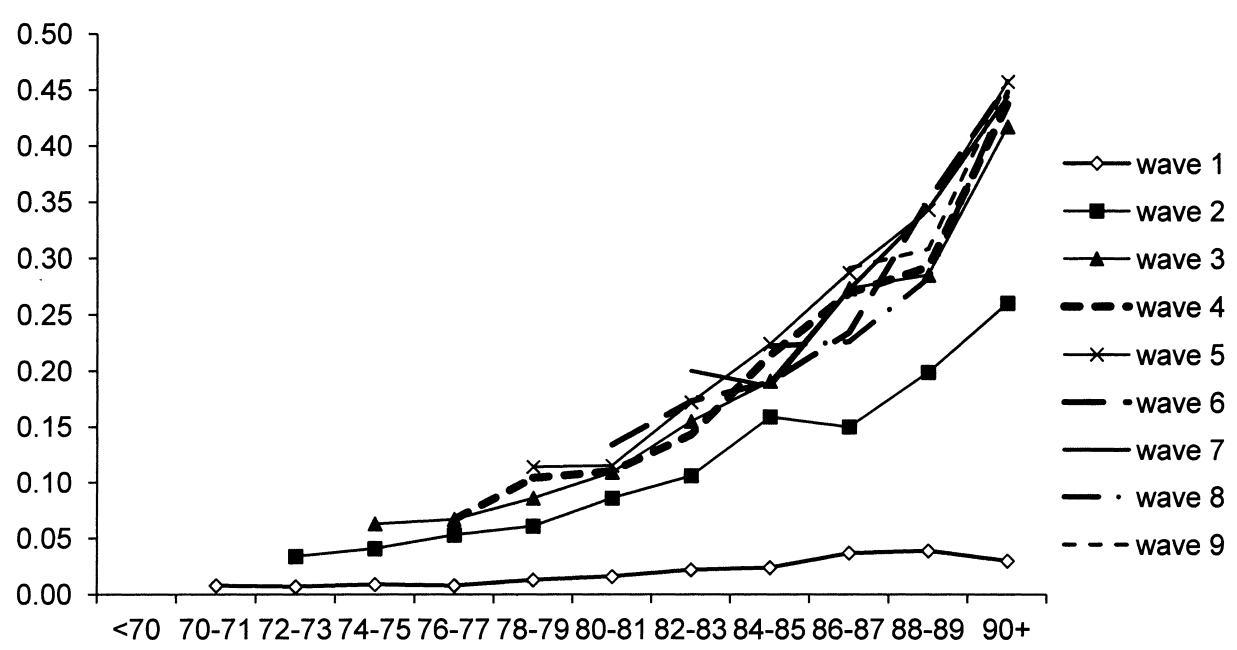

Fig. 2.3 Fraction with any nursing home stay in last two years, by age: AHEAD cohort (with exit interviews)

Because of the importance of relatively short-term stays, researchers will underestimate nursing home exposure if their estimates rely on interviews with respondents who are alive in each wave. Respondents who were living in the community in a wave, experienced a nursing home stay following that wave, and died before the succeeding wave would not be recorded as having a nursing home stay. In the exit interview, the proxy respondent is asked about nursing home stays since the previous interview. We find that including them increases substantially the estimate of nursing home exposure. Figure 2.3 illustrates their importance. Consider those 86-87 years old in wave 2. Adding those who were interviewed in wave 1 and would have been $86-87$ years old in wave 2 had they survived shows that nursing home exposure in that larger group was 15 percent between waves 1 and 2 , rather than 12 percent among survivors to wave 2 (figure 2.2). Thus the use of the exit interview increased nursing home exposure by 3.5 percentage points or 32 percent.

\subsection{Age Prevalence of Nursing Home Stays and Lifetime Exposure}

\subsubsection{Age Prevalence of Nursing Home Stays and Nursing Home Use}

In the calculations of the age prevalence, we exclude the first two waves of data for each cohort because of the lack of representation of the nursing home population as previously discussed. We pool all remaining waves and cohorts and apply respondent weights. Table 2.2 shows the age prevalence for two measures: the fraction residing in a nursing home at the time of interview and the fraction with any nursing home stay in the previous two 


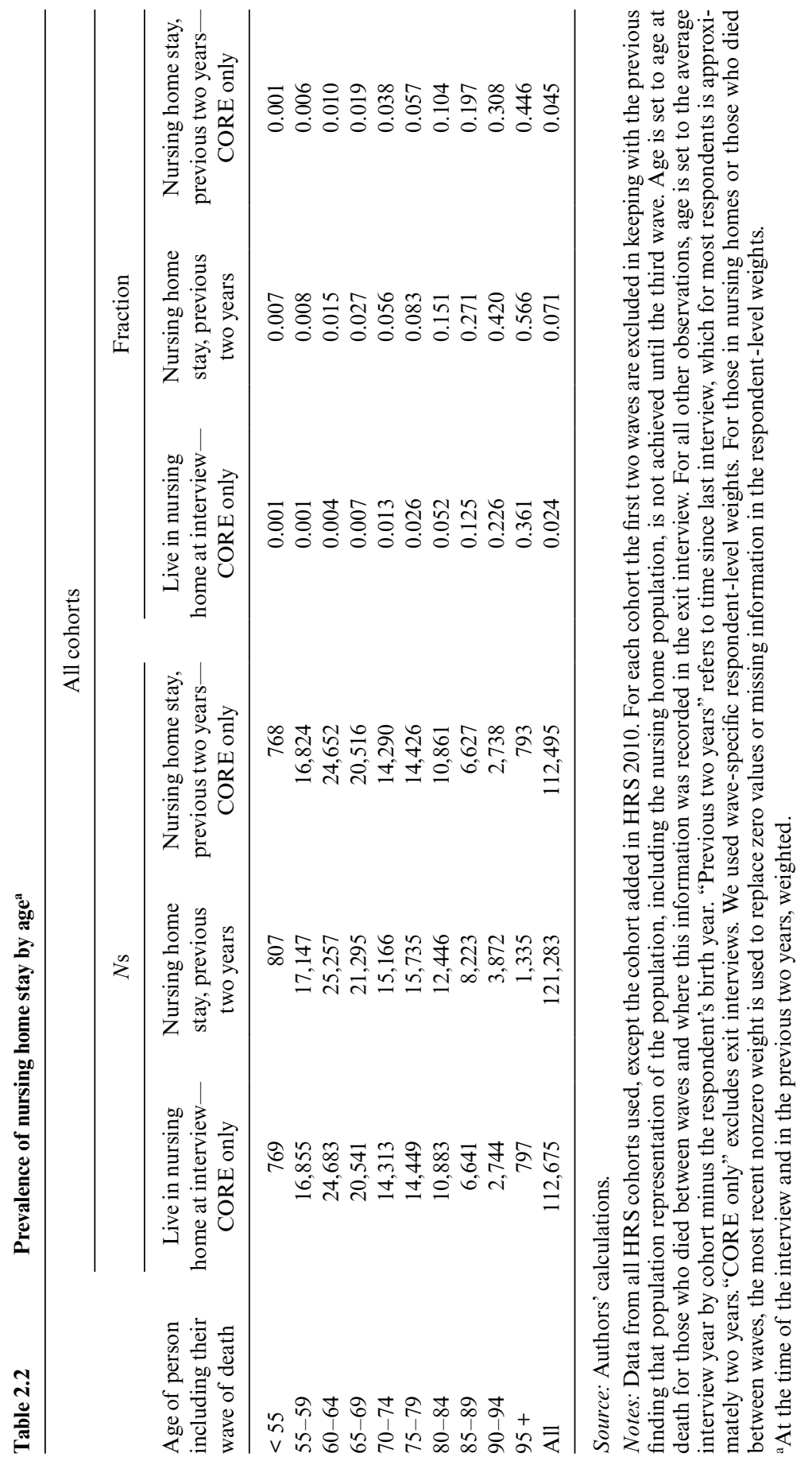


years. For the latter we included a column incorporating the information from the exit interviews and one without ("core only") to highlight once again the much higher prevalence obtained when including the information from the exit interviews. The exit interviews capture the information of those respondents who died between waves that would otherwise be missed. Because nursing home stays are most prevalent toward the end of life, this is an important omission.

The fraction residing in a nursing home at the time of interview is low, less than 1 percent, at ages less than seventy. At ages seventy and older the fraction approximately doubles with every five-year age band up to age 90-94 when it reaches 23 percent. Among those surviving to age ninety-five and older, the fraction residing in a nursing home is 36 percent. The measure assessed at the time of the interview reflects just a moment in time, whereas the next column measures any nursing home stays that have occurred in the previous two years, and includes the exit interviews. At ages up to eighty-four the fraction with any nursing home stay in the previous two years is higher than the moment in time measure by a factor of three or more, reflecting the importance of short-term stays at relatively younger ages. At the oldest ages it is 20 percentage points higher than the moment in time measure. Among those 90-94 years old, 42 percent resided in a nursing home sometime in the previous two years, and among those age ninety-five or older, 57 percent did so. The final column has similar statistics but does not use the exit interviews. Overall the exposure to nursing homes is 2.6 percentage points lower, but at some ages the discrepancy is much greater: at ages 90-94 it is 11.2 percentage points lower.

Table 2.3 provides the average by age band of the total number of nights spent in a nursing home in the previous two years, again both with and without consideration of the exit interviews. For the number of nights the differences between the two columns are noticeable, but not particularly large. The explanation is that the exit interviews capture the information for those who died between waves for whom the period covered since the last interview is on average just one year and not two years as for the remainder of the sample.

Focusing on the column that incorporates the exit interviews, the total number of nights spent in a nursing home in the previous two years averaged over the entire sample (unconditional on nursing home stay) approximately doubles every five years between the ages of fifty-five and ninety-four, reaching 131 nights for those age ninety to ninety-four. Among those age ninety-five or older, the average number of nights in a nursing home is 203.

\subsubsection{Lifetime Risk of a Nursing Home Stay}

Using the long panel dimension of the HRS, we show in table 2.4 estimates of lifetime exposure obtained from the raw data without - for nowaddressing the issue of left or right censoring. We start with the HRS cohort 
Number of nights spent in nursing home, by age ${ }^{a}$

\begin{tabular}{|c|c|c|c|c|}
\hline \multirow[b]{3}{*}{$\begin{array}{l}\text { Age of person } \\
\text { including their } \\
\text { wave of death }\end{array}$} & \multicolumn{4}{|c|}{ All cohorts } \\
\hline & \multicolumn{2}{|c|}{$N \mathrm{~s}$} & \multicolumn{2}{|c|}{ Mean } \\
\hline & $\begin{array}{l}\text { Nights in nursing } \\
\text { home, previous } \\
\text { two years }\end{array}$ & $\begin{array}{l}\text { Nights in nursing } \\
\text { home, previous two } \\
\text { years-CORE only }\end{array}$ & $\begin{array}{l}\text { Nights in nursing } \\
\text { home, previous } \\
\text { two years }\end{array}$ & $\begin{array}{l}\text { Nights in nursing } \\
\text { home, previous two } \\
\text { years-CORE only }\end{array}$ \\
\hline$<55$ & 807 & 768 & 0.64 & 0.52 \\
\hline $55-59$ & 17,139 & 16,818 & 0.84 & 0.72 \\
\hline $60-64$ & 25,236 & 24,643 & 2.45 & 1.74 \\
\hline $65-69$ & 21,265 & 20,501 & 4.13 & 3.53 \\
\hline $70-74$ & 15,139 & 14,273 & 8.63 & 6.75 \\
\hline $75-79$ & 15,676 & 14,395 & 15.74 & 12.55 \\
\hline $80-84$ & 12,358 & 10,812 & 33.59 & 26.89 \\
\hline $85-89$ & 8,111 & 6,557 & 67.03 & 58.32 \\
\hline $90-94$ & 3,784 & 2,685 & 130.55 & 117.26 \\
\hline $95+$ & 1,311 & 780 & 202.97 & 204.47 \\
\hline All & 120,826 & 112,232 & 16.37 & 12.04 \\
\hline
\end{tabular}

Notes: Data from all HRS cohorts used, except the cohort added in HRS 2010. For each cohort the first two waves are excluded in keeping with the previous finding that population representation of the population, including the nursing home population, is not achieved until the third wave. Age is set to age at death for those who died between waves and where this information was recorded in the exit interview. For all other observations, age is set to the average interview year by cohort minus the respondent's birth year. "Previous two years" refers to time since last interview, which for most respondents is approximately two years. "CORE only" excludes exit interviews. We used wave-specific respondent-level weights. For those in nursing homes or those who died between waves, the most recent nonzero weight is used to replace zero values or missing information in the respondent-level weights.

${ }^{\text {aAll }}$ cohorts, weighted.

born between 1931 and 1941 and observed from 1992 until 2010. In the youngest age band of HRS (age 50-54), about 20 percent had died by 2010. About 10 percent had a nursing home stay, and the average number of stays was 0.18 , indicating that some individuals had multiple stays. The average number of nights was twenty-three, including those with no nursing home exposure. These statistics increase with age. For all HRS cohort respondents the average number of stays was 0.26 and the average number of nights was about 33 , indicating that the typical stay was about 130 nights. Among those who died before wave 10, eighteen years after wave 1, 26 percent had a nursing home stay and the average length of stay was eighty-three nights.

Table 2.5 shows the same statistics for the older AHEAD cohort. In the AHEAD cohort, mortality was essentially complete for those initially age $80-84$. In that group 60 percent were in a nursing home at some time. The average number of nights was just under 310 . With the exception of the youngest age group in the AHEAD cohort, the difference in nursing home exposure between everyone initially in an age band and those who died 
Table 2.4 HRS cohort: Mortality and cumulative nursing home frequencies, unconditional and conditional on dying between waves 2 and 10, weighted

\begin{tabular}{lccccc}
\hline Age wave 1 & $N$ & Died waves 2-10 & Any stay 2-10 & Number stays & Number nights \\
\hline $50-54$ & 3,889 & 0.20 & 0.10 & 0.18 & 22.6 \\
$55-59$ & 4,178 & 0.25 & 0.14 & 0.30 & 34.9 \\
$60-64$ & 1,371 & 0.33 & 0.18 & 0.36 & 58.0 \\
All & 9,438 & 0.24 & 0.13 & 0.26 & 33.3 \\
& & Conditional on dying in between waves 2 & and 10 & \\
$50-54$ & 828 & 1.00 & 0.26 & 0.52 & 78.8 \\
$55-59$ & 1,115 & 1.00 & 0.29 & 0.67 & 73.7 \\
$60-64$ & 484 & 1.00 & 0.30 & 0.68 & 108.1 \\
All & 2,427 & 1.00 & 0.28 & 0.62 & 82.5 \\
\hline
\end{tabular}

Notes: Includes exit interviews. Respondent-level weight from baseline interview used throughout.

Table 2.5 AHEAD cohort: Mortality and cumulative nursing home frequencies, unconditional and conditional on dying between waves 2 and 9

\begin{tabular}{lrcccc}
\hline Age wave 1 & $N$ & $\begin{array}{c}\text { Died waves } \\
2-9\end{array}$ & $\begin{array}{c}\text { Any stay } \\
2-9\end{array}$ & Number stays & Number nights \\
\hline $70-74$ & 2,676 & 0.67 & 0.42 & 0.86 & 147.6 \\
$75-79$ & 2,031 & 0.83 & 0.55 & 1.18 & 250.5 \\
$80-84$ & 1,493 & 0.94 & 0.60 & 1.32 & 308.1 \\
$85-89$ & 723 & 0.99 & 0.65 & 1.60 & 352.2 \\
$90-94$ & 231 & 0.99 & 0.66 & 1.25 & 307.7 \\
$95+$ & 68 & 1.00 & 0.57 & 0.97 & 311.0 \\
All & 7,222 & 0.81 & 0.52 & 1.13 & 235.3 \\
& & Conditional on dying between waves 2 and 9 & \\
$70-74$ & 1,802 & 1.00 & 0.49 & 1.02 & 166.8 \\
$75-79$ & 1,678 & 1.00 & 0.58 & 1.25 & 256.6 \\
$80-84$ & 1,400 & 1.00 & 0.62 & 1.35 & 311.4 \\
$85-89$ & 715 & 1.00 & 0.65 & 1.61 & 350.7 \\
$90-94$ & 229 & 1.00 & 0.66 & 1.25 & 309.6 \\
$95+$ & 68 & 1.00 & 0.57 & 0.97 & 311.0 \\
All & 5,892 & 1.00 & 0.57 & 1.24 & 255.1 \\
\hline
\end{tabular}

Notes: Includes exit interviews. Respondent-level weight from baseline interview used throughout.

before 2010 is not substantial, indicating that right censoring is not very important; that is, among those initially age seventy-five or older we are close to observing rest-of-lifetime nursing home risk. For example, in the age group 75-79, 55 percent used a nursing home at some time before 2010. Thus, among those who survive to age 75-79, a lower bound on rest-of-life lifetime nursing home exposure is 55 percent. There is, of course left censoring, which would increase the lifetime risk of those who survive to that age. 


\section{Nonparametric Estimation of Lifetime Risk of any Nursing Home Stay}

Our nonparametric estimation of nursing home exposure is based on figure 2.4. It combines nursing home exposure and transition probabilities from three cohorts. The main and central cohort is AHEAD wave 1 respondents whose initial ages were seventy to seventy-four. By 2010, at which time the cohort would have been eighty-seven to ninety-one years old, 67 percent of that cohort had died and 33 percent were still alive. Among those who died, 49 percent were in a nursing home sometime prior to death. Among the 33 percent who survived, 29 percent had nursing home exposure. To estimate the effect of right censoring among the 71 percent who survived and had no nursing home exposure, we use the AHEAD wave 1 respondents whose initial ages were eighty-five to eighty-nine. By 2010 all of that cohort had died, and 65 percent were in a nursing home prior to death but following the initial wave in 1993. These were "fresh" nursing home exposures because AHEAD wave 1 only sampled those in the community. Combining these probabilities, we estimate nursing home exposure of the initial AHEAD cohort age $70-74$ to be 57.6 percent $(0.67 * 0.49+$ $0.33 *(0.29+0.71 * 0.65)){ }^{4}$

This figure needs to be adjusted in several ways. The initial AHEAD sample in 1993 excluded residents in nursing homes. Some initial AHEAD respondents age 70-74 had prior nursing home exposure. Some persons died before reaching age 70-74 and had nursing home exposure. To make these adjustments we use the HRS cohort. Combining HRS waves for respondents 50-54 years of age, we find that 20 percent died before reaching age seventy-two and that 26 percent of those who died were in a nursing home sometime prior to death. Among survivors, 1.3 percent were in a nursing home at age 70-74, and among those not in a nursing home, 5 percent had previously been in a nursing home. Combining these conditional probabilities with the AHEAD probabilities, we estimate that the lifetime exposure of HRS respondents initially age 50-54 in 1992 will be 53.4 percent when the last such respondent has died.

These calculations do not consider nursing home exposure prior to entering HRS. While we have no data on nursing home exposure prior to the initial wave of HRS, in the subsequent waves of HRS nursing home exposure is infrequent. For example, among those initially age $50-54$ in HRS in 1992, 0.2 percent had nursing home exposure between waves 1 and 2 , and an additional 0.6 percent had nursing home exposure between waves 2 and 3 .

4. This calculation assumes that, conditional on being in the community at wave 1 and on reaching age 85-89 with no intervening nursing home exposure, the probability of nursing home exposure prior to death is the same as the probability of nursing home exposure of those in wave 1 age $85-89$. 


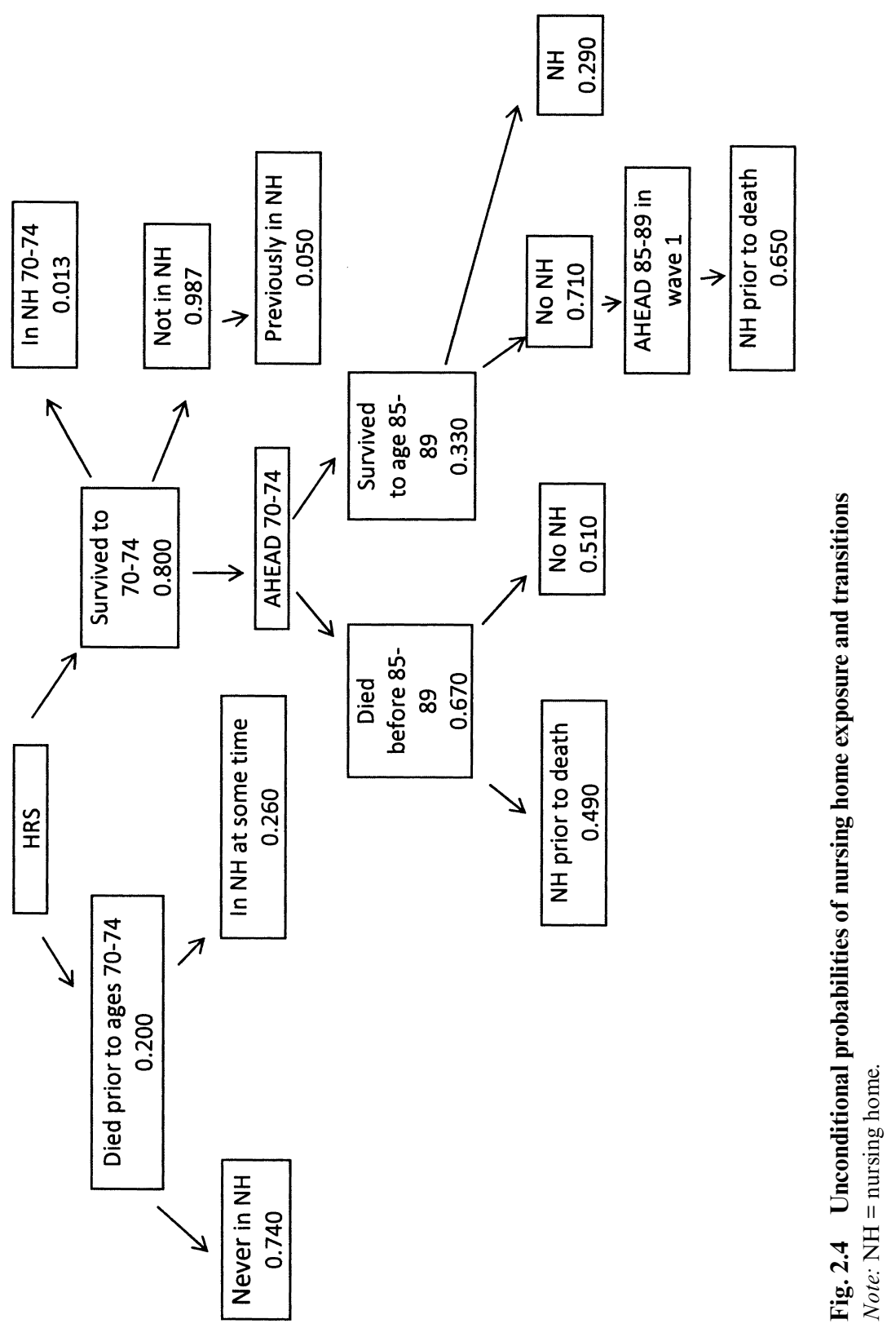




\subsection{Methodology of Parametric Estimation of Lifetime Exposure}

We develop a simulation model that allows us to compute the lifetime distribution of nursing home stays and their length. Let $i=1, \ldots, N$ denote respondents and $t=1, \ldots, T_{i}$ denote the wave during which an interview takes place. Each wave takes place approximately every two years. ${ }^{5}$

We use two key pieces of information from the HRS in building the model. First, we use reports of any nursing home stays in the previous two years and reports of mortality to construct a combined status variable, $d_{i t}$, which can take four values : (a) alive and living in the community, (b) alive and living in a nursing home, (c) died in the community, and (d) died in a nursing home. Because states (c) and (d) are absorbing, four transitions are possible from each of the two states where the respondent is alive ( $a$ and $b$ ). We define the probability of entering state $j=1, \ldots, 4$ at $t+1$ given a current state $k=$ 1,2 at $t$, a vector of sociodemographic characteristics $x_{i}$, and age $a_{i t}$ using a multinomial logit :

$$
P\left(d_{i t+1}=j \mid x_{i}, a_{i t}, d_{i, t}=k\right)=\frac{\exp \left(x_{i} \gamma_{1, j, k}+\gamma_{a, j, k}\left(a_{i t}\right)\right)}{\sum_{j^{\prime}} \exp \left(x_{i} \gamma_{1, j^{\prime}, k}+\gamma_{a, j, k}\left(a_{i t}\right)\right.} .
$$

We do not impose parametric restrictions on the functions $\gamma_{a, j, k}$ and instead use categorical variables for age bands. Because data is scarce at older ages, we use five-year age groups from age 50 to 100 . After obtaining estimates of the parameters by maximum likelihood, we interpolate linearly the age functions at single years of age intervals. We extrapolate for ages between 100 and 110 (maximum age in simulations).

Second, we use reports of the number of days spent in a nursing home between waves. Because the time of entry or exit is unknown and could vary on average depending on the state at $t$ and the state at $t+1$, we estimate separate models of the log of number of visits $v_{i t}$ between waves for (a) individuals transiting from living in the community to either living [or] died in a nursing home, and (b) for those transiting from living in a nursing home to the same two destinations. The models estimated take the form

$$
\begin{aligned}
& \log v_{i t}=x_{i} \beta_{j, k}+\beta_{a, j, k}\left(a_{i t}\right)+\varepsilon_{i t}, \\
& j=2,4, k=1,2
\end{aligned}
$$

where $\varepsilon_{i t}$ is assumed normally distributed with mean 0 and variance $\sigma_{\varepsilon, j, k}^{2}$. Again, we assume the age functions are given by a set of categorical variables for different age bands (five-year age groups). We use interpolation for inter-

5. In future research, we plan to adjust the models presented to account for heterogeneity in exposure time (differences in time between interviews). 
vening years. Given the log formulation of the conditional mean and the assumption of normality, the expected number of visits is given by

$$
E\left[v_{i t} \mid x_{i}, a_{i t}, j, k\right]=\exp \left(x_{i} \beta_{j, k}+\beta_{a, j, k}\left(a_{i t}\right)+\frac{1}{2} \sigma_{\varepsilon, j, k}^{2}\right) .
$$

The estimated equations for the transition probabilities and the process for the number of days in a nursing home can then be used to simulate histories of nursing home stays. The initial population for the simulation is those respondents 50-55 years of age in the War Babies and Early Baby Boomers cohorts. We draw with replacement 50,000 sets of sociodemographic characteristics $x_{i}$. We consider education, race, marital status at age fifty, number of children, whether the individual had daughters, and an indicator for whether the respondent was ever a smoker. We then simulate histories using the processes estimated earlier. Finally, we compute statistics of interest from the simulation using survey weights from the two waves used as the starting point.

\subsection{Results for Parametric Model}

\subsubsection{Estimation}

We first present estimation results of the transition models. We then present results for the number of days spent in a nursing home between waves. We obtain both sets of estimates using the HRS data as described in section 2.2. We use all cohorts in estimation, except the youngest (Mid-Baby Boomers) that was only inducted into the HRS in 2010. For the two cohorts who were older at baseline, AHEAD and CODA, we exclude the first two waves that each responded to so that our estimation sample does not suffer from underrepresentation of the nursing home population.

In table 2.6, we present multinomial logit estimates of transitions from the community to a nursing home. The reference category is living in the community (i.e., not in a nursing home). Since all age parameters go from negative to positive, this establishes that the fraction alive in the community decreases with age. Not surprisingly, transitions either to a nursing home or death increase in frequency with age. This is shown in figure 2.5 , first panel, where we see that the average probability of staying in the community decreases from close to 100 percent for a fifty-year-old respondent to less than 50 percent for a ninety-five-year-old respondent. Before age sixty-five, most transitions out of the community are the result of death outside of nursing homes or residence in a nursing home. After age seventy-five, many more respondents die in a nursing home. The transition rate from the community to a nursing home increases steeply after age seventy.

Results from table 2.6 indicate that males face transition probabilities significantly different from those females face. Compared to females, males 


\begin{tabular}{|c|c|c|c|}
\hline Variables & Alive in $\mathrm{NH}$ & Died, not NH & Died in $\mathrm{NH}$ \\
\hline \multicolumn{4}{|l|}{ Age (65 omitted) } \\
\hline 50 & $\begin{array}{l}-1.872 * * * \\
(0.188)\end{array}$ & $\begin{array}{l}-1.052^{* * *} \\
(0.104)\end{array}$ & $\begin{array}{l}-1.967^{* * *} \\
(0.292)\end{array}$ \\
\hline 55 & $\begin{array}{c}-1.363^{* * *} \\
(0.113)\end{array}$ & $\begin{array}{l}-0.814 * * * \\
(0.074)\end{array}$ & $\begin{array}{c}-1.353^{* * *} \\
(0.168)\end{array}$ \\
\hline 60 & $\begin{array}{c}-0.733 * * * \\
(0.096)\end{array}$ & $\begin{array}{c}-0.370 * * * \\
(0.067)\end{array}$ & $\begin{array}{c}-0.603^{* * *} \\
(0.137)\end{array}$ \\
\hline 70 & $\begin{array}{l}0.663^{* * *} \\
(0.085)\end{array}$ & $\begin{array}{l}0.217 * * * \\
(0.073)\end{array}$ & $\begin{array}{l}0.729 * * * \\
(0.124)\end{array}$ \\
\hline 75 & $\begin{array}{l}1.141^{* * *} \\
(0.078)\end{array}$ & $\begin{array}{l}0.776^{* * *} \\
(0.065)\end{array}$ & $\begin{array}{l}1.258 * * * \\
(0.112)\end{array}$ \\
\hline 80 & $\begin{array}{l}1.779 * * * \\
(0.076)\end{array}$ & $\begin{array}{l}1.175^{* * *} \\
(0.066)\end{array}$ & $\begin{array}{l}1.917 * * * \\
(0.109)\end{array}$ \\
\hline 85 & $\begin{array}{l}2.338^{* * * *} \\
(0.080)\end{array}$ & $\begin{array}{l}1.723^{* * *} \\
(0.072)\end{array}$ & $\begin{array}{l}2.776 * * * \\
(0.110)\end{array}$ \\
\hline 90 & $\begin{array}{l}2.693^{* * *} \\
(0.102)\end{array}$ & $\begin{array}{l}2.233^{* * *} \\
(0.097)\end{array}$ & $\begin{array}{l}3.582 * * * \\
(0.123)\end{array}$ \\
\hline 95 & $\begin{array}{l}2.710^{* * * *} \\
(0.207)\end{array}$ & $\begin{array}{l}3.032 * * * \\
(0.166)\end{array}$ & $\begin{array}{l}4.135^{* * *} \\
(0.189)\end{array}$ \\
\hline Male & $\begin{array}{l}-0.414^{* * *} \\
(0.045)\end{array}$ & $\begin{array}{l}0.382 * * * \\
(0.037)\end{array}$ & $\begin{array}{l}0.205^{* * *} \\
(0.056)\end{array}$ \\
\hline \multicolumn{4}{|c|}{ Education (less than high school omitted) } \\
\hline High school & $\begin{array}{c}-0.0748 \\
(0.050)\end{array}$ & $\begin{array}{l}-0.357 * * * \\
(0.044)\end{array}$ & $\begin{array}{c}-0.125^{*} \\
(0.064)\end{array}$ \\
\hline College & $\begin{array}{l}-0.156 * * * \\
(0.052)\end{array}$ & $\begin{array}{l}-0.513 * * * \\
(0.045)\end{array}$ & $\begin{array}{c}-0.399 * * * \\
(0.068)\end{array}$ \\
\hline Nonwhite & $\begin{array}{c}-0.0275 \\
(0.058)\end{array}$ & $\begin{array}{l}0.206 * * * \\
(0.046)\end{array}$ & $\begin{array}{l}-0.01 \\
(0.076)\end{array}$ \\
\hline Married at age 50 & $\begin{array}{l}-0.317^{* * * *} \\
(0.051)\end{array}$ & $\begin{array}{l}-0.144 * * * \\
(0.047)\end{array}$ & $\begin{array}{c}-0.352^{* * *} \\
(0.067)\end{array}$ \\
\hline \multicolumn{4}{|c|}{ Number of children (1-3 omitted) } \\
\hline No children & $\begin{array}{c}-0.284 \\
(0.231)\end{array}$ & $\begin{array}{c}0.0159 \\
(0.186)\end{array}$ & $\begin{array}{c}0.199 \\
(0.225)\end{array}$ \\
\hline $4+$ children & $\begin{array}{c}-0.0585 \\
(0.044)\end{array}$ & $\begin{array}{l}0.0973 * * \\
(0.038)\end{array}$ & $\begin{array}{c}-0.183^{* * *} \\
(0.059)\end{array}$ \\
\hline Has daughters & $\begin{array}{c}-0.00284 \\
(0.058)\end{array}$ & $\begin{array}{c}-0.0696 \\
(0.052)\end{array}$ & $\begin{array}{c}-0.0976 \\
(0.072)\end{array}$ \\
\hline Ever smoker & $\begin{array}{l}0.244 * * * \\
(0.042)\end{array}$ & $\begin{array}{l}0.612 * * * \\
(0.041)\end{array}$ & $\begin{array}{l}0.442 * * * \\
(0.058)\end{array}$ \\
\hline Constant & $\begin{array}{l}-3.640^{* * *} \\
(0.101)\end{array}$ & $\begin{array}{c}-3.702 * * * \\
(0.088)\end{array}$ & $\begin{array}{l}-4.584^{* * *} \\
(0.138)\end{array}$ \\
\hline Observations & 108,186 & & \\
\hline Log-likelihood & -31166 & & \\
\hline Degrees freedom & 54 & & \\
\hline Chi-square & 10,109 & & \\
\hline
\end{tabular}

Notes: Multinomial logit parameter estimates and standard errors. The base category is living in the community. NH refers to nursing homes.

***Significant at the 1 percent level.

**Significant at the 5 percent level.

*Significant at the 10 percent level. 

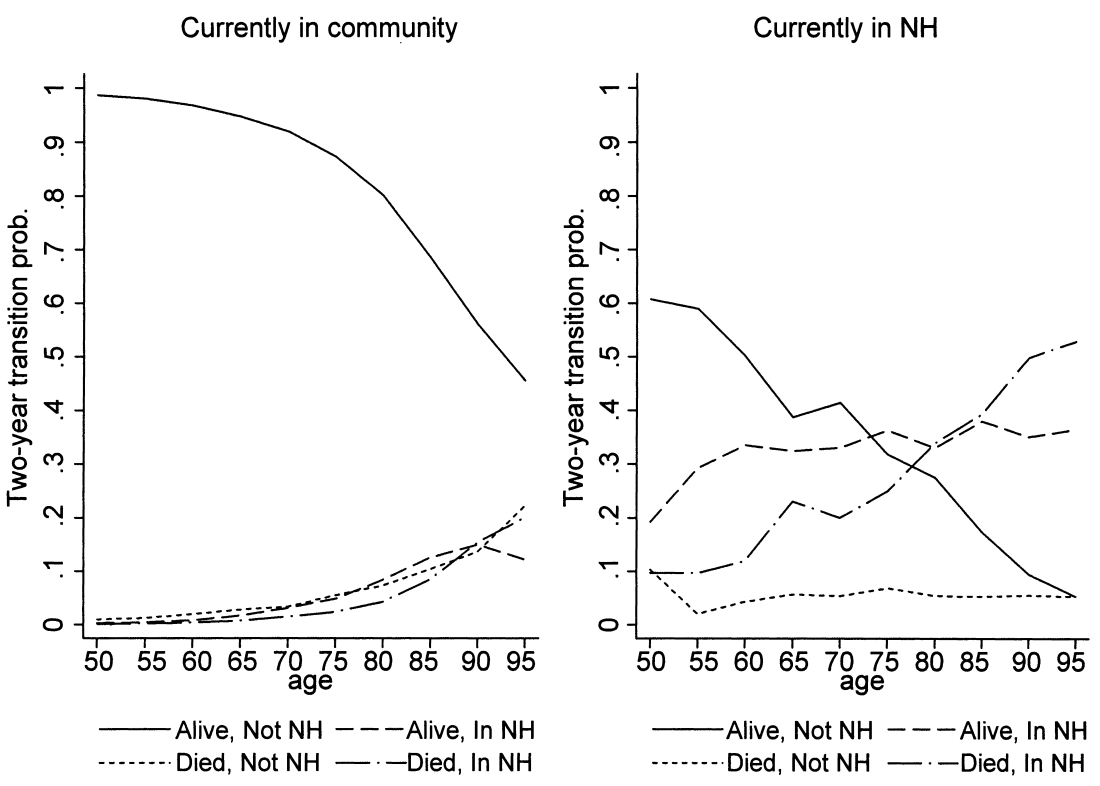

Fig. 2.5 Transition probabilities across states

who had been living in the community have a much lower chance of living in a nursing home two years (i.e., one survey wave) later. They also have a significantly higher risk of dying from one wave to the next, reflecting males' lower life expectancy - and, accordingly, higher death rates. This increased death probability is tilted toward death in the community: males are more likely to die in either setting, but almost twice as likely to die outside a nursing home.

Table 2.6 also shows that education, in particular college education, protects against both mortality and entering a nursing home. This reflects in part the SES-health gradient. Nonwhite respondents are more likely to die outside a nursing home but are about as likely as white respondents to enter a nursing home. Being married at age fifty also protects against entering a nursing home. Of course, the natural channel for this association is that one spouse may be able to provide help to the other who needs it. In addition, those married at age fifty are less likely to die, either in a nursing home or in the community. Interestingly, being childless does not appear to increase the probability of entering a nursing home (relative to having 1-3 children). Having four or more children appears to increase the probability that the respondent will die outside a nursing home, relative to dying in a nursing home. Having daughters appears to have no statistically detectable effect.

In table 2.7, we present multinomial logit estimates of transitions from 


\begin{tabular}{|c|c|c|c|}
\hline Variables & Alive, not NH & Died, not NH & Died in $\mathrm{NH}$ \\
\hline \multicolumn{4}{|l|}{ Age (65 omitted) } \\
\hline 50 & $\begin{array}{c}0.807 \\
(0.635)\end{array}$ & $\begin{array}{c}0.918 \\
(0.917)\end{array}$ & $\begin{array}{c}-0.409 \\
(0.883)\end{array}$ \\
\hline 55 & $\begin{array}{c}0.552 * \\
(0.292)\end{array}$ & $\begin{array}{l}-1.14 \\
(0.796)\end{array}$ & $\begin{array}{c}-0.813^{*} \\
(0.422)\end{array}$ \\
\hline 60 & $\begin{array}{c}0.283 \\
(0.229)\end{array}$ & $\begin{array}{r}-0.392 \\
(0.467)\end{array}$ & $\begin{array}{c}-0.699 * * \\
(0.300)\end{array}$ \\
\hline 70 & $\begin{array}{c}-0.00192 \\
(0.196)\end{array}$ & $\begin{array}{c}-0.103 \\
(0.365)\end{array}$ & $\begin{array}{r}-0.154 \\
(0.223)\end{array}$ \\
\hline 75 & $\begin{array}{c}-0.386^{* *} \\
(0.183)\end{array}$ & $\begin{array}{r}0.0381 \\
(0.322)\end{array}$ & $\begin{array}{c}-0.0505 \\
(0.198)\end{array}$ \\
\hline 80 & $\begin{array}{l}-0.468 * * * \\
(0.177)\end{array}$ & $\begin{array}{c}-0.0415 \\
(0.317)\end{array}$ & $\begin{array}{l}0.400^{* *} \\
(0.186)\end{array}$ \\
\hline 85 & $\begin{array}{l}-1.057 * * * \\
(0.182)\end{array}$ & $\begin{array}{c}-0.175 \\
(0.316)\end{array}$ & $\begin{array}{l}0.427 * * \\
(0.184)\end{array}$ \\
\hline 90 & $\begin{array}{l}-1.582 * * * \\
(0.224)\end{array}$ & $\begin{array}{c}-0.0102 \\
(0.342)\end{array}$ & $\begin{array}{l}0.766^{* * *} \\
(0.194)\end{array}$ \\
\hline 95 & $\begin{array}{l}-2.205^{* * *} \\
(0.376)\end{array}$ & $\begin{array}{c}-0.0373 \\
(0.445)\end{array}$ & $\begin{array}{l}0.809 * * * \\
(0.234)\end{array}$ \\
\hline Male & $\begin{array}{c}0.0932 \\
(0.100)\end{array}$ & $\begin{array}{l}0.640^{* * * *} \\
(0.162)\end{array}$ & $\begin{array}{l}0.398 * * * \\
(0.093)\end{array}$ \\
\hline \multicolumn{4}{|c|}{ Education (less than high school omitted) } \\
\hline High school & $\begin{array}{l}0.390 * * * \\
(0.108)\end{array}$ & $\begin{array}{c}-0.0948 \\
(0.183)\end{array}$ & $\begin{array}{c}-0.221 * * \\
(0.095)\end{array}$ \\
\hline College & $\begin{array}{l}0.703^{* * *} \\
(0.114)\end{array}$ & $\begin{array}{c}0.233 \\
(0.184)\end{array}$ & $\begin{array}{c}-0.240 * * \\
(0.103)\end{array}$ \\
\hline Nonwhite & $\begin{array}{c}-0.256^{*} \\
(0.131)\end{array}$ & $\begin{array}{c}0.203 \\
(0.203)\end{array}$ & $\begin{array}{l}0.00941 \\
(0.116)\end{array}$ \\
\hline Married at age 50 & $\begin{array}{l}0.364^{* * *} \\
(0.110)\end{array}$ & $\begin{array}{c}0.239 \\
(0.188)\end{array}$ & $\begin{array}{c}0.0589 \\
(0.096)\end{array}$ \\
\hline \multicolumn{4}{|c|}{ Number of children (1-3 omitted) } \\
\hline No children & $\begin{array}{c}-0.705 \\
(0.574)\end{array}$ & $\begin{array}{c}0.979 \\
(0.612)\end{array}$ & $\begin{array}{c}0.224 \\
(0.434)\end{array}$ \\
\hline $4+$ children & $\begin{array}{c}0.0996 \\
(0.097)\end{array}$ & $\begin{array}{l}0.00471 \\
(0.167)\end{array}$ & $\begin{array}{c}0.018 \\
(0.091)\end{array}$ \\
\hline Daughter & $\begin{array}{c}0.0948 \\
(0.128)\end{array}$ & $\begin{array}{c}0.123 \\
(0.211)\end{array}$ & $\begin{array}{r}-0.0509 \\
(0.107)\end{array}$ \\
\hline Ever smoker & $\begin{array}{c}-0.237 * * \\
(0.095)\end{array}$ & $\begin{array}{c}0.0734 \\
(0.162)\end{array}$ & $\begin{array}{c}0.0923 \\
(0.086)\end{array}$ \\
\hline Constant & $\begin{array}{c}-0.406^{*} \\
(0.224)\end{array}$ & $\begin{array}{l}-2.370 * * * \\
(0.390)\end{array}$ & $\begin{array}{c}-0.407^{*} \\
(0.216)\end{array}$ \\
\hline Observations & 3,798 & & \\
\hline Log-likelihood & -4443 & & \\
\hline Degrees freedom & 54 & & \\
\hline Chi-square & 569.3 & & \\
\hline
\end{tabular}

Notes: Multinomial logit parameter estimates and standard errors. The base category is living in a nursing home.

***Significant at the 1 percent level.

**Significant at the 5 percent level. 
a nursing home to one of the four states (living in the community, living in a nursing home, dying in the community, dying in a nursing home). The reference category is alive in a nursing home. From the estimates, we see that the exit probability from a nursing home to the community generally decreases with age. In figure 2.5 , second panel, we see that the estimates imply that this probability goes from 60 percent at age fifty to less than 20 percent at age eighty-five. Hence, persistence increases with age, which likely reflects an increase in the severity of disabilities for those in a nursing home. Mortality rates in a nursing home are much higher than in the community. This can be seen in figure 2.5 . For example, summing the two curves, the probability of dying either in the community or in a nursing home is 20 percent at age fifty, while it increases to about 60 percent by age ninety-five.

Table 2.7 indicates that gender differences are somewhat different for transitions originating in a nursing home. Specifically, and in contrast to the previous state of origin, males do not face a significantly different probability of exiting a nursing home alive. As well, their probability of dying between the two waves is much higher than females, with the difference being tilted again toward dying outside a nursing home. Gender differences are, however, markedly larger than they were for transitions originating in the community. This could perhaps be explained by a more severe disability for males when they finally enter a nursing home.

As for the other characteristics considered and likely to affect transitions out of nursing homes, college education appears to increase the likelihood of return to the community. Education also decreases the probability of dying in a nursing home, as was the case for those individuals who were initially living in the community (table 2.6). Being nonwhite reduces the probability of exiting a nursing home. Family background has no significant effect on exits from nursing homes, excepting those individuals who were married at age fifty, who are more likely to leave a nursing home for the community. Finally, being a smoker reduces the probability of returning to the community.

Estimates in tables 2.6 and 2.7 will play out in the simulations. On one hand, some characteristics such as education reduce the probability of entry into a nursing home and increase the exit probability from a nursing home. On the other hand, education also reduces the likelihood of dying, hence prolonging the exposure to nursing home risk. In the end, these opposing forces will yield ambiguous predictions of the effect of education on lifetime prevalence of nursing home stays.

We also look at the intensity of nursing home stays between waves. For this we turn to table 2.8, which reports estimation results for the number of days spent in nursing homes. Each column in the table reports estimates of the effect of variables on the log of the number of days spent in a nursing home for four different pairs of origin and destination states. 


\begin{tabular}{|c|c|c|c|c|}
\hline \multirow[b]{2}{*}{ Variables } & \multicolumn{2}{|c|}{ From community } & \multicolumn{2}{|c|}{ From nursing home } \\
\hline & $\begin{array}{l}\text { Living } \\
\text { in NH }\end{array}$ & $\begin{array}{l}\text { Died } \\
\text { in NH }\end{array}$ & $\begin{array}{l}\text { Living } \\
\text { in NH }\end{array}$ & $\begin{array}{l}\text { Died } \\
\text { in } \mathrm{NH}\end{array}$ \\
\hline \multicolumn{5}{|l|}{ Age (65 omitted) } \\
\hline 50 & $\begin{array}{c}-0.308 \\
(0.319)\end{array}$ & $\begin{array}{c}-0.299 \\
(0.442)\end{array}$ & $\begin{array}{c}0.946 \\
(0.795)\end{array}$ & $\begin{array}{r}-0.768 \\
(0.957)\end{array}$ \\
\hline 55 & $\begin{array}{c}-0.0242 \\
(0.186)\end{array}$ & $\begin{array}{c}-0.0822 \\
(0.265)\end{array}$ & $\begin{array}{c}0.333 \\
(0.368)\end{array}$ & $\begin{array}{c}-0.556 \\
(0.473)\end{array}$ \\
\hline 60 & $\begin{array}{c}-0.233 \\
(0.158)\end{array}$ & $\begin{array}{c}-0.192 \\
(0.215)\end{array}$ & $\begin{array}{c}0.0803 \\
(0.268)\end{array}$ & $\begin{array}{c}0.351 \\
(0.345)\end{array}$ \\
\hline 70 & $\begin{array}{c}0.025 \\
(0.138)\end{array}$ & $\begin{array}{c}-0.0379 \\
(0.191)\end{array}$ & $\begin{array}{l}0.465^{* *} \\
(0.225)\end{array}$ & $\begin{array}{l}0.00768 \\
(0.238)\end{array}$ \\
\hline 75 & $\begin{array}{c}0.221 * \\
(0.126)\end{array}$ & $\begin{array}{c}0.0739 \\
(0.174)\end{array}$ & $\begin{array}{l}0.433^{* *} \\
(0.205)\end{array}$ & $\begin{array}{c}0.174 \\
(0.205)\end{array}$ \\
\hline 80 & $\begin{array}{l}0.487^{* * * *} \\
(0.122)\end{array}$ & $\begin{array}{l}0.474^{* * *} \\
(0.169)\end{array}$ & $\begin{array}{l}0.633^{* * *} \\
(0.197)\end{array}$ & $\begin{array}{l}0.00344 \\
(0.189)\end{array}$ \\
\hline 85 & $\begin{array}{l}0.694^{* * *} \\
(0.128)\end{array}$ & $\begin{array}{l}0.511^{* * *} \\
(0.168)\end{array}$ & $\begin{array}{l}0.828^{* * *} \\
(0.194)\end{array}$ & $\begin{array}{c}0.233 \\
(0.186)\end{array}$ \\
\hline 90 & $\begin{array}{l}1.046^{* * *} \\
(0.160)\end{array}$ & $\begin{array}{l}0.438^{* *} \\
(0.182)\end{array}$ & $\begin{array}{l}0.857^{* * * *} \\
(0.213)\end{array}$ & $\begin{array}{c}0.348 * \\
(0.190)\end{array}$ \\
\hline 95 & $\begin{array}{l}0.922 * * * \\
(0.313)\end{array}$ & $\begin{array}{c}0.413 \\
(0.256)\end{array}$ & $\begin{array}{l}1.234^{* * *} \\
(0.261)\end{array}$ & $\begin{array}{l}0.507 * * \\
(0.221)\end{array}$ \\
\hline Male & $\begin{array}{c}-0.0905 \\
(0.071)\end{array}$ & $\begin{array}{c}-0.185^{* *} \\
(0.084)\end{array}$ & $\begin{array}{c}-0.0724 \\
(0.107)\end{array}$ & $\begin{array}{c}-0.126 \\
(0.087)\end{array}$ \\
\hline \multicolumn{5}{|c|}{ Education (less than high school omitted) } \\
\hline High school & $\begin{array}{c}-0.0266 \\
(0.079)\end{array}$ & $\begin{array}{c}-0.124 \\
(0.094)\end{array}$ & $\begin{array}{r}-0.147 \\
(0.105)\end{array}$ & $\begin{array}{l}-0.1 \\
(0.091)\end{array}$ \\
\hline College & $\begin{array}{c}-0.206^{* *} \\
(0.081)\end{array}$ & $\begin{array}{c}-0.187^{*} \\
(0.100)\end{array}$ & $\begin{array}{l}-0.321^{* * *} \\
(0.113)\end{array}$ & $\begin{array}{c}-0.108 \\
(0.099)\end{array}$ \\
\hline Nonwhite & $\begin{array}{l}0.442 * * * \\
(0.093)\end{array}$ & $\begin{array}{c}0.0021 \\
(0.116)\end{array}$ & $\begin{array}{l}0.480^{* * * *} \\
(0.127)\end{array}$ & $\begin{array}{c}0.0821 \\
(0.114)\end{array}$ \\
\hline Married at age 50 & $\begin{array}{c}-0.0993 \\
(0.081)\end{array}$ & $\begin{array}{c}0.0881 \\
(0.101)\end{array}$ & $\begin{array}{l}0.00698 \\
(0.104)\end{array}$ & $\begin{array}{c}-0.176^{*} \\
(0.093)\end{array}$ \\
\hline \multicolumn{5}{|c|}{ Number of children (omitted 1-3) } \\
\hline No children & $\begin{array}{r}-0.366 \\
(0.359)\end{array}$ & $\begin{array}{c}-0.104 \\
(0.328)\end{array}$ & $\begin{array}{c}0.388 \\
(0.530)\end{array}$ & $\begin{array}{c}-0.479 \\
(0.392)\end{array}$ \\
\hline $4+$ children & $\begin{array}{l}-0.222 * * * \\
(0.070)\end{array}$ & $\begin{array}{c}0.0693 \\
(0.090)\end{array}$ & $\begin{array}{c}0.0623 \\
(0.099)\end{array}$ & $\begin{array}{c}-0.119 \\
(0.088)\end{array}$ \\
\hline Daughter & $\begin{array}{l}-0.224^{* *} \\
(0.092)\end{array}$ & $\begin{array}{c}-0.200 * \\
(0.107)\end{array}$ & $\begin{array}{c}-0.260^{* *} \\
(0.120)\end{array}$ & $\begin{array}{c}-0.099 \\
(0.101)\end{array}$ \\
\hline Ever smoker & $\begin{array}{c}0.114^{*} \\
(0.068)\end{array}$ & $\begin{array}{c}-0.0481 \\
(0.087)\end{array}$ & $\begin{array}{c}-0.0938 \\
(0.095)\end{array}$ & $\begin{array}{c}-0.0432 \\
(0.083)\end{array}$ \\
\hline Constant & $\begin{array}{l}3.829 * * * \\
(0.162)\end{array}$ & $\begin{array}{l}3.488^{* * *} \\
(0.204)\end{array}$ & $\begin{array}{l}5.283^{* * *} \\
(0.231)\end{array}$ & $\begin{array}{l}5.207 * * * \\
(0.214)\end{array}$ \\
\hline Observations & 2,579 & 1,488 & 1,272 & 1,226 \\
\hline Log-likelihood & -4882 & -2710 & -2349 & -2074 \\
\hline Degrees of freedom & 18 & 18 & 18 & 18 \\
\hline$R$-square & 0.0662 & 0.0399 & 0.0608 & 0.034 \\
\hline
\end{tabular}

Notes: Regression of the log of number of days in nursing homes between interviews. Each column refers to a different specification, estimated on the sample of respondents either living in the community or in a nursing home at $t$ and who either survive in a nursing home at $t+1$ or die in a nursing home by $t+1$. Standard errors below point estimates.

$* * *$ Significant at the 1 percent level.

**Significant at the 5 percent level.

*Significant at the 10 percent level. 


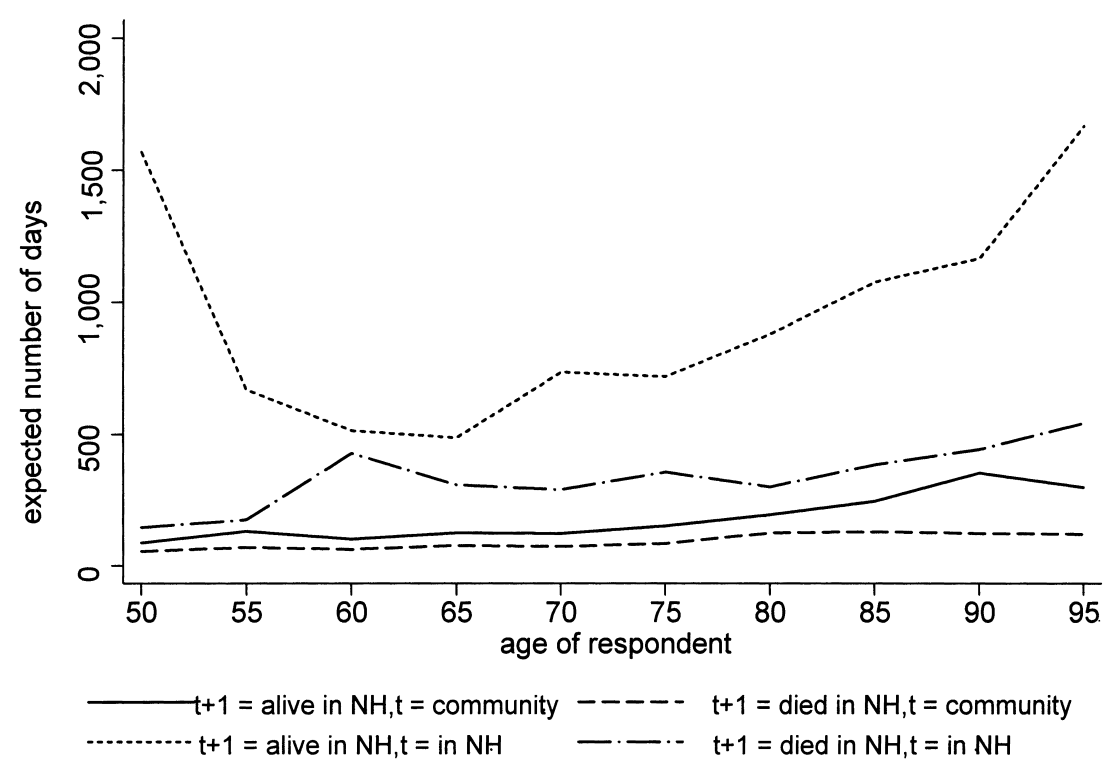

Fig. 2.6 Expected number of days in $\mathrm{NH}$ conditional on being in $\mathrm{NH}$ next wave

The first and second columns present results for transitions that originate from the community. In the first column, respondents are observed living in a nursing home at $t+1$, while in the second they died in a nursing home by $t+1$. We see for both these transitions an increase with age in the number of days spent in a nursing home. Figure 2.6 reports the average expected number of days spent in a nursing home by age. We can observe for both these transitions a small number of days (from roughly 100 days at age fifty to 350 days at age ninety-five) relative to other transitions that originate from nursing homes (see following). This partly reflects the fact that respondents experiencing the two transitions originating in the community will, on average, enter nursing homes in the middle of the time interval between waves. The average number of days is also smaller for those who died between waves. For these two transitions originating in the community, college education and having daughters appear to reduce the number of days spent in a nursing home, whereas being nonwhite and ever being a smoker both appear to increase it for those who are still living in a nursing home in the next wave.

The third and fourth columns of table 2.8 report regression results for transitions that originate from nursing homes. Not surprisingly, the number of days spent in a nursing home is much higher for those respondents, as shown in figure 2.6. Furthermore, the number of days increases with age (except for individuals staying in a nursing home at younger ages, for 
Table 2.9

Simulated lifetime exposure to nursing homes (NH) with and without exit interviews

\begin{tabular}{lcc}
\hline & With exit interviews & Without exit interviews \\
\hline Prob(any stay) & 0.577 & 0.368 \\
$E$ (no. of days) & 214.7 & 136.6 \\
$E$ (no. of days| any stay) & 371.9 & 370.4 \\
Prob(dies in NH) & 0.477 & 75.9 \\
Age first entry NH & 76.8 & \\
\hline
\end{tabular}

Notes: Simulated outcomes from age 50, for 50,000 respondents drawn randomly from the pool of HRS respondents age 50-55 in the War Babies and Early Baby Boomers cohorts. Sample weights used.

whom the number is initially higher). In terms of characteristics, having a college degree and having daughters both decrease the number of days spent in a nursing home for individuals staying in a nursing home across waves. On the other hand, being nonwhite increases this number of days.

\subsubsection{Simulation}

We simulate the lifetime nursing home histories for an initial population with characteristics drawn from the pool of respondents 50-55 years of age in the War Babies and Early Baby Boomers cohorts. We draw (with replacement) 50,000 observations. We then simulate two-year transitions up to a maximum of 110 years of age.

In table 2.9, we present simulation results for five outcomes: the simulated probability of any stay, the average number of days in a nursing home (both conditional on having at least one stay and unconditional), the probability of dying in a nursing home, and, finally, the age at which individuals first enter a nursing home. We report these outcomes under two scenarios. The first includes the information from the exit interviews. Hence, we know whether-and when - someone died in a nursing home. For the second scenario we ignore the information from the exit interviews, so that nursing home stays prior to death are unobserved. Hence, we reclassify state $j=4$ (Died this wave, in nursing home last two years) when computing outcomes to state $j=3$ (Died this wave, no nursing home stay last two years). So all individuals who died will be attributed state $j=3$.

Results are striking, especially when comparing the two scenarios (i.e., with and without exit interviews). When excluding exit interviews, the probability of ever experiencing a nursing home stay is 36.8 percent, which is consistent with prior literature (Kemper and Murtaugh 1991). When using exit interviews however, this probability increases to 57.7 percent. The average number of days spent in a nursing home increases from 136.6 to 214.7. 


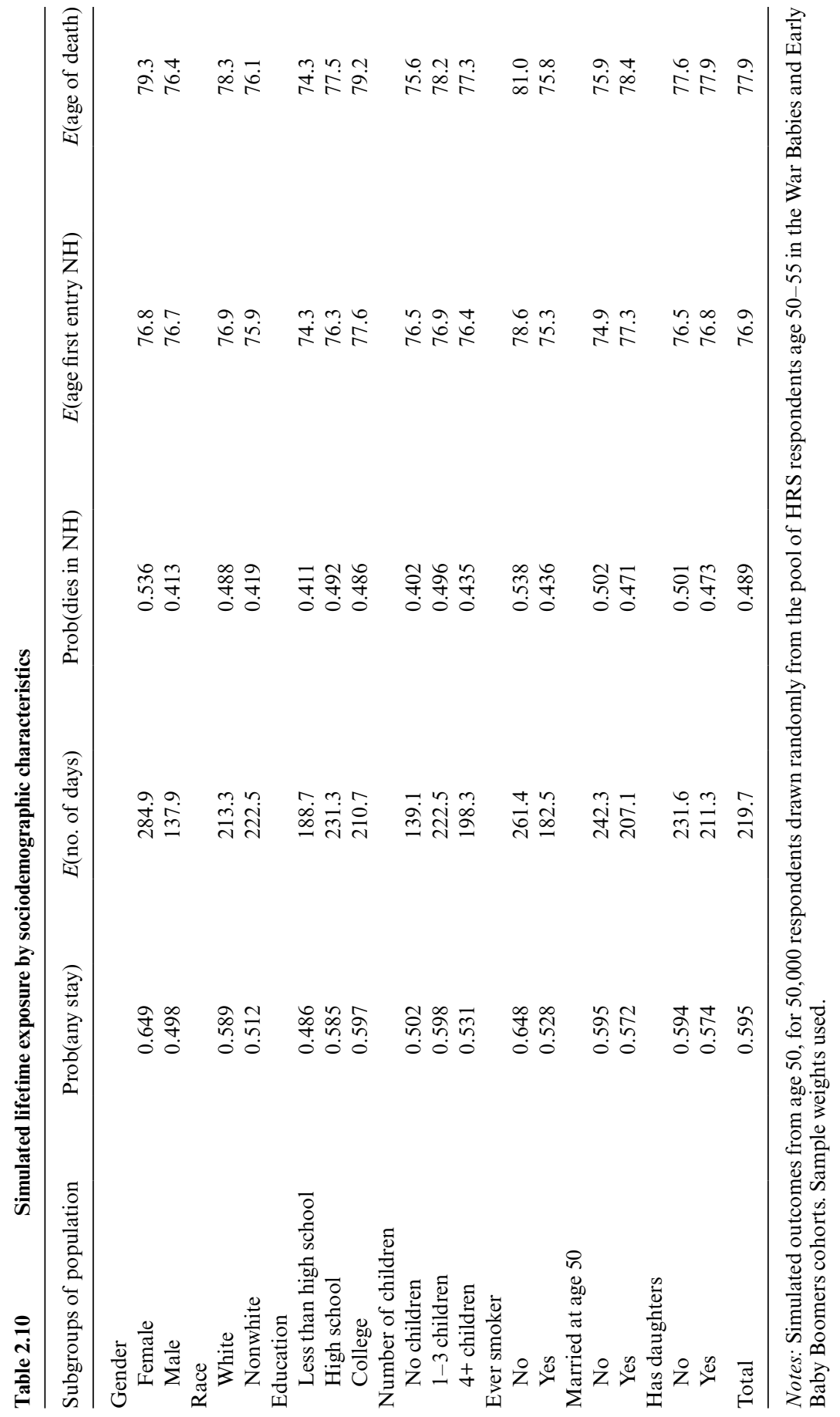


Conditional on having one stay, the average number of days spent over the lifetime of a fifty-year-old is 371.9 days, or just over a year. The probability of dying in a nursing home is 47.7 percent. Finally, the average age at first entry in a nursing home is 76.8 when using exit interviews, and 75.9 without. Overall, exit interviews are crucial in accurately establishing the lifetime prevalence and intensity of nursing home stays.

In table 2.10 , we present table 2.9 results by sociodemographic groups. The lifetime prevalence of nursing home stays differs considerably by gender. Females face a 64.9 percent probability of having at least one stay, compared to 49.8 percent for males. This is due to both their longer life expectancy and to the fact that at every age, they face a higher probability of entering a nursing home (perhaps because their husband died before them). Females' average number of days spent in a nursing home is 284.9, compared to 137.9 for males. The probability that females will die in a nursing home is 53.6 percent, against 41.3 percent for males. Nonwhites have a lower probability of entering a nursing home, in part because of their lower life expectancy.

Differences in terms of education are ambiguous, as predicted earlier. Individuals with less than a high school diploma have a lower risk of ever entering a nursing home. Most of this difference is explained by their lower life expectancy (74.3 years, compared to 77.5 for those with a high school diploma and 79.2 for those with a college degree). At the same time, those with college degrees have a slightly lower lifetime exposure to nursing homes, driven in part by a delayed age of entry into nursing homes. Interestingly, individuals without children have a lower risk of ever entering a nursing home. Those who were a smoker at some point in their life are much less likely to ever enter a nursing home, but this effect is also driven by a lower life expectancy ( 75.8 compared to 81.0 for nonsmokers). We find little differences in lifetime prevalence by marital status or according to the presence of daughters.

Because some of the characteristics considered are correlated, the question arises as to whether differences remain over one characteristic when controlling for the others. Hence, we regress the simulated lifetime outcomes from age fifty on individuals' sociodemographic characteristics. This may be interpreted as a reduced-form equation of the transition and intensity equations mentioned earlier. Results are presented in table 2.11.

Results reveal that all else being equal, males have a 13.8 percent lower probability of ever entering a nursing home, and also spend 57.1 percent less time in a nursing home. Education effects are mostly driven by the distinction between having completed high school or not. Individuals with either high school or college degrees have a 7 to 8 percent higher chance of ever staying in a nursing home. Nonwhites, individuals without children or with many children, and those who were ever smokers are also less likely to enter a nursing home at any point in their life. 
Table 2.11

Regression of lifetime measures on sociodemographic characteristics

\begin{tabular}{lcc}
\hline Variables & $P($ any stay $)$ & $E(\log$ days|any stay $)$ \\
\hline Male & $-0.138^{* * *}$ & $-0.571^{* * *}$ \\
& $(0.004)$ & $(0.022)$ \\
Education (less than high school omitted) & & -0.034 \\
High school & $0.0717^{* * *}$ & $(0.032)$ \\
& $(0.006)$ & $-0.0732^{* *}$ \\
College & $0.0830^{* * *}$ & $(0.031)$ \\
& $(0.006)$ & $0.127^{* * *}$ \\
Nonwhite & $-0.0591^{* * *}$ & $(0.027)$ \\
& $(0.005)$ & $-0.0606^{* *}$ \\
Married at age 50 & $-0.0259^{* * *}$ & $(0.027)$ \\
& $(0.006)$ & $-0.466^{* * *}$ \\
Number of children (1-3 omitted) & $-0.0528^{* * *}$ & $(0.105)$ \\
No children & $(0.020)$ & -0.0151 \\
4+ children & $-0.0507^{* * *}$ & $(0.024)$ \\
Has daughters & $(0.005)$ & $-0.0945^{* * *}$ \\
Ever smoker & 0.0026 & $(0.029)$ \\
Constant & $(0.006)$ & $-0.156^{* * *}$ \\
Observations & $-0.0860^{* * *}$ & $(0.022)$ \\
\hline
\end{tabular}

Notes: Simulated outcomes from age 50 for 50,000 respondents drawn randomly from the pool of HRS respondents age 50-55 in the War Babies and Early Baby Boomers cohorts are regressed on other observed characteristics. The first model for the probability of any stay in a nursing home is estimated using a logit model, and average marginal effects on the probability of any stay are reported. In the second model, the log of the number of days spent in a nursing home, conditional on having at least one stay, is regressed on the same characteristics. Standard errors are reported in parentheses.

***Significant at the 1 percent level.

**Significant at the 5 percent level.

*Significant at the 10 percent level.

\subsection{Discussion}

Our estimates of lifetime risk are larger than those previously reported. Perhaps the most widely cited estimate is 37 percent in the population that survives to age sixty-five (Kemper and Murtaugh 1991). While our estimates are not directly comparable because of differences in initial age, mortality and nursing home exposure between ages fifty and sixty-five are much too small to account for the difference. The Kemper and Murtaugh estimate is based on the 1986 Mortality Followback Survey, which asked informants about the lifetime nursing home exposure of a sample of deceased in 1986. While this design likely obtains information about recent nursing home stays 
that is equivalent to the HRS exit interviews, it is probable that the informant either does not know about more distant stays or does not remember those stays. Indeed Kemper and Murtaugh state that such errors are likely to lead to underreporting "which would have caused us to underestimate lifetime nursing home use."

The study by Dick, Garber, and MaCurdy (1994) is similar to ours in method. Based on the National Long-Term Care Survey, they estimate transition probabilities between residence in the community, residence in a nursing home and death, and then via simulation estimate that lifetime risk is 35 percent conditional on survival to age sixty-five. Because of the complexities of the study design of the NLTCS, they combine three samples from the NLTCS, which leaves open the possibility that the populations represented do not mesh properly to form a complete population-representative sample. Indeed, addressing the reason for the lack of good estimates at the time of their paper, Dick, Garber, and MaCurdy state,

Failure to address cumulative utilization in representative samples undoubtedly reflects the inadequacy of much existing data. No individual data sets have sufficiently complete longitudinal data to infer comprehensive measures of nursing home utilization for a nationally representative, random sample of elderly Americans. Ideally such a study would enroll a large number of elderly individuals, track them for several years, and obtain complete information on the number and timing of nursing home stays during the period of observation. (p. 366)

A major strength of this paper is the availability of the HRS, which satisfies the requirements of Dick, Garber, and MaCurdy. Further, the HRS used consistent, transparent recruitment methods over time, and the survey instrument is also consistent over time. The HRS exerted considerable effort in tracking subjects so the rate of complete unit loss over time is low: just 3.5 percent of our central cohort, the AHEAD cohort, which forms the basis for the bulk of the sample, has an unknown vital status (table 2.1), and 91 percent is either alive and in wave 10, or is dead with an exit interview.

Brown and Finkelstein (2004) estimate lifetime risk of nursing home exposure conditional on survival to age sixty-five to be 39 percent. $^{6}$ Their estimate is based on simulations of a model of Robinson of transitions between health states in the NLTCS 1982, 1984, 1989, and 1994 (Robinson 1999). Because the model predicts health status rather than nursing home status, additional data from the 1985 National Nursing Home Survey are used to link probabilistically health status to residence. As with Dick, Garber, and MaCurdy, the use of multiple data sets provides an opportunity of a mismatch between the populations represented by the different data sets.

6. Appendix table A1, Brown and Finkelstein (2004). 
Table 2.12

Percentage residing in nursing homes at the time of interview, weighted

\begin{tabular}{rrrrrrrrr}
\hline & 1996 & 1998 & 2000 & 2002 & 2004 & 2006 & 2008 & 2010 \\
\hline $55-59$ & 0.2 & 0.2 & 0.3 & 0.1 & 0.2 & - & 0.1 & 0.1 \\
$60-64$ & 0.2 & 0.3 & 0.3 & 0.2 & 0.3 & 0.3 & 0.4 & 0.7 \\
$65-69$ & 0.6 & 0.5 & 0.9 & 0.6 & 0.8 & 0.7 & 0.5 & 0.8 \\
$70-74$ & - & 1.0 & - & 1.0 & 1.5 & 1.4 & 1.6 & 1.1 \\
$75-79$ & - & 2.6 & 2.5 & 2.3 & 2.1 & 2.8 & 2.6 & 3.1 \\
$80-84$ & - & 6.3 & 5.6 & 5.0 & 4.3 & 5.6 & 4.6 & 5.2 \\
$85+$ & - & 18.5 & 18.9 & 18.8 & 18.2 & 16.0 & 14.3 & 15.0 \\
\hline
\end{tabular}

Note: Does not include exit interviews.

It is unclear whether any of the three estimates use an equivalent of our exit interviews. However, it is striking that if we exclude the data from the exit interviews, we obtain an estimate of lifetime exposure conditional on survival to age fifty of 37 percent, which is similar to reported estimates in the literature. If we include the exit interview information, which accounts for stays at the end of life, our estimates are 53 and 59 percent for the nonparametric and simulations methods respectively.

Based on ten waves of data, our nonparametric method approaches a complete description of the nursing home experience of a cohort. As such that description does not rely on assumptions such as stationarity of the process of nursing home entry or exit. However, to extend the results to a statement about the nursing home experience of previous or future cohorts does require stationarity. Further, because we have not modeled any time trend or cohort effects in the transition probabilities, the parametric methods require stationarity even as a description of our cohorts. Table 2.12 provides some evidence about stationarity. The table only includes observations from waves in which a particular cohort has been observed for three or more, because waves 1 and 2 do not adequately represent the nursing home population. Although there was a decline in the rate of nursing home residency among those eighty-five or older between 2004 and 2008 , the overall trend is a modest decrease of 3.5 percentage points over a fourteen-year period. In a number of the other age bands the rate increased. We conclude that there is little overall trend in the prevalence of nursing home residence in the HRS, so that stationarity of the process is a reasonable assumption.

\subsection{Conclusion}

In this chapter, we use both parametric and nonparametric approaches to calculate the lifetime risk of nursing home stays using rich data from the Health and Retirement Study. Both provide a similar estimate: a 
fifty-year-old has a 53-59 percent chance of ever staying in a nursing home, which is considerably higher than that reported in previous literature. Conditional on entering a nursing home, the average number of nights spent in a nursing home over the lifetime is just over a year (370 days). This average estimate hides considerable heterogeneity as the distribution is highly skewed.

Our results also highlight that there are two competing forces that affect lifetime risk: nursing home risk and mortality risk. Both of these depend in a nontrivial way on sociodemographic characteristics. For example, smokers have a higher risk of entering a nursing home conditional on being alive. But since they also face higher mortality risks, this reduces lifetime exposure to nursing home risk. We find that females, white, and nonsmokers face the highest risks of ever entering a nursing home.

\section{References}

Arling, G., S. Hagan, and H. Buhaug. 1992. "The Feasibility of a Public-Private Long-Term Care Financing Plan.” Medical Care 30:699.

Brown, Jeffrey R., and Amy Finkelstein. 2004. "Supply or Demand: Why is the Market for Long-Term Care Insurance So Small?” NBER Working Paper no. 10782, Cambridge, MA.

- 2008. "The Interaction of Public and Private Insurance: Medicaid and the Long-Term Care Insurance Market.” American Economic Review 98 (3): 1083-102.

Cohen, M. A., E. J. Tell, and S. S. Wallack. 1986. "The Lifetime Risks and Costs of Nursing Home Use Among the Elderly." Medical Care 41 (6): 785-92.

Dick, A., A. M. Garber, and T. MaCurdy. 1994. "Forecasting Nursing Home Utilization of Elderly Americans." In Studies in the Economics of Aging, edited by David Wise, 365-94. Chicago: University of Chicago Press.

Juster, F. T., and R. Suzman. 1995. "An Overview of the Health and Retirement Study." Journal of Human Resources 30 (Suppl.): S7-S56.

Kelly, Anne, Jessamyn Conell-Price, Kenneth Covinsky, Irena Cenzer, Anna Chang, W. J. Boscardin, and Alexander Smith. 2010. "Length of Stay for Older Adults Residing in Nursing Homes at the End of Life." Journal of the American Geriatrics Society 58 (9): 1701-6.

Kemper, P., and C. M. Murtaugh. 1991. "Lifetime Use of Nursing Home Care.” New England Journal of Medicine 324:595-600.

Liang, J., X. Liu, E. Tu, and N. Whitelaw. 1996. "Probabilities and Lifetime Durations of Short-Stay Hospital and Nursing Home Use in the United States, 1985." Medical Care 34 (10): 1018-36.

Robinson, Jim. 1999. "A Long-Term-Care Status Transition Model.” In The OldAge Crisis-Actuarial Opportunities: The 1996 Bowles Symposium, Society of Actuaries Monograph M-RS99-1.

Spillman, B. C., and J. Lubitz. 2002. "New Estimates of Lifetime Nursing Home Use: Have Patterns of Use Changed?" Medical Care 40 (10): 965-75. 